\title{
Author Correction: Estimation of losses in solar energy production from air pollution in China since 1960 using surface radiation data
}

Bart Sweerts (iD, Stefan Pfenninger (iD, Su Yang, Doris Folini, Bob van der Zwaan and Martin Wild

Correction to: Nature Energy https://doi.org/10.1038/s41560-019-0412-4, published online 8 July 2019.

In the version of this Article originally published, the units of 'Total electricity yield' and 'Potential electricity gain' in Table 1 were incor-

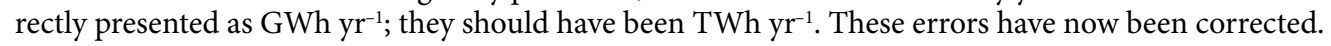

Published online: 12 July 2019

https://doi.org/10.1038/s41560-019-0445-8 